\title{
3D Quantitative and Qualitative Structure-Activity Relationships of the $\delta$-Opioid Receptor Antagonists
}

\author{
Sun Chun, Jee-Young Lee, ${ }^{\dagger+*}$ Seong-Gu Ro, ${ }^{\$}$ Ki-Woong Jeong, ${ }^{\dagger}{ }^{\text {Yangmee Kim, }{ }^{\star} \text { and Chang-Ju Yoon }}{ }^{\circ}$ \\ Department of Chemistry, The Catholic Lniversity of Korea, Puchon $420-743$, Korea. ${ }^{*}$ E-mail: cjoonacatholicac.kr \\ ${ }^{\dagger}$ Department of Bioscience and Biotechnology, and Bio. Holectiar Informatics Center, Konkuk Uninersity, Seoul 143-701, Korea \\ "E-mail: jyoungáakonktk.ac.kr \\ ${ }^{\prime}$ CrustalGenomics, Inc, Seoul 138-736, Korea \\ Received December 4, 2007
}

\begin{abstract}
Antagonists of the $\delta$-opioid receptor are effective in overcoming resistance against analgesic drugs such as morphine. To identify novel antagonists of the $\delta$-opioid receptor that display high potency and low resistance. we performed 3D-QSAR analy'sis using chemical feature-based pharmacophore models. Chemical features for $\delta$-opioid receptor antagonists were generated using quantitative (Catalyst/HypoGen) and qualitative (Catalyst/ HipHop) approaches. For HypoGen analysis. we collected 16 peptide and 16 non-peptide antagonists as the training set. The best-fit pharnacophore hypotheses of the two antagonist models comprised identical features. including a hydrophobic aromatic (HAR), a hydrophobic (HY), and a positive ionizable (PI) function. The training set of the HipHop model was constnicted with three launched opioid dnugs. The best hypothesis from HipHop included four features: an HAR. an HY, a hydrogen bond donor (HBD). and a PI function. Based on these results. we confirm that HY. HAR and PI features are essential for effective antagonism of the $\delta$-opioid receptor. and determine the appropriate pharmacophore to design such antagonists.
\end{abstract}

Key Words : GPCR, Opioid receptor, Analgesic drug, Catalyst. QSAR

\section{Introduction}

Opioid receptors comprise part of the G-protein coupled receptor (GPCR) superfamily. ${ }^{1}$ and are characterized by seven transmembrane regions. Three major types of opioid receptors $\left(\delta, \kappa\right.$, and $\mu$ ) have been identified to date. ${ }^{2}$ but their mechanisms of action remain to be established. The $\mu$ opioid receptor is located in the central nervous sy'stem (CNS), while the $\delta$-opioid receptor is related the peripheral nervous sy'stem. ${ }^{\text {j.t }}$ Their endogenous ligands. "opioids" (enkephalins. endorphins. dynorphins. and endomorphins) are involved in several important physiological functions. including nociception, autonomic reflexes. neuroendocrine effects. and thermoregulation. ${ }^{5.6}$

Several analgesic drugs. including morphine. are commonly used to reduce pain stemming from cancer or nervous damage. However. resistance to these drugs results in serious problems. which diminishes their anesthetic effects. ${ }^{7.8}$ Considerable efforts have been devoted to obtain opioids that operate via specific receptors. with a view to identifying analgesics possessing a reduced side-effect profile relative to morphine? "While all three major opioid receptors are important targets for developing therapies to treat acute pain. only the $\mu$-opioid receptor appears to be involved in morphine tolerance and addiction ${ }^{10.11}$ However. opiate tolerance and physical dependence can be blocked by $\delta$ opioid receptor antagonists without compromising antinociception induced by drug interactions with $\mu$-opioid receptors. The development of selective antagonists of $\delta$ opioid receptors over the past decade has revealed interesting physiological roles of this receptor. including a modulatory effect on the $\mu$-opioid receptor. Moreover. $\delta$ opioid receptor knockout mice display no tolerance to morphine, and an antagonist of $\delta$-opioid effectively abolishes resistance against analgesic drugs. ${ }^{13-15}$ Thus. the development of agents with potent $\delta$-opioid receptor antagonist activity is essential in modern healthcare. ${ }^{16.17}$

In the Catalyst ${ }^{\text {TM }}$ (Accelry's. San Diego. CA), a pharmacophore is referred to as a "hypothesis" to reflect the fact that generated models do not necessarily represent the true pharmacophore ${ }^{18}$ Catalyst/HypoGen uses a combination of QSAR and pharmacophore methods. ${ }^{18.19}$ This analysis requires a full range of test compounds (from active to inactive). along with their measured activities derived from experimental data. The combination technique not only identifies a query compound as 'active' or 'inactive' in the tradition of a pharmacophore model. but also predicts activity based on regression of the training dataset analogous to the capability of a QSAR model. On the other hand. Catalyst/HipHop attempts to identify common molecular features based on the superposition of active compounds. ${ }^{2(1.21}$ This method merely requires the input of active molecules without use of activity data. and results are ranked by tendency of molecular fitting to the proposed hypothesis. as well as matched features.?

In this point. there is a medical need to develop 3DQSAR $^{22.23}$ models and identify pharmacophores to establish the essential structural and electronic features for $\delta$-opioid receptor antagonist activity:

In this study, we performed a structure-based approach to identify the optimal pharmacophore from a set of ligands using 3D-QSAR to refine the receptor model and increase 
Table 1. Training set of peptide $\delta$-opioid antagonists of Dnint-Tic derivatives for HypoGen generation (Activities are presented as $K_{1}$ values)

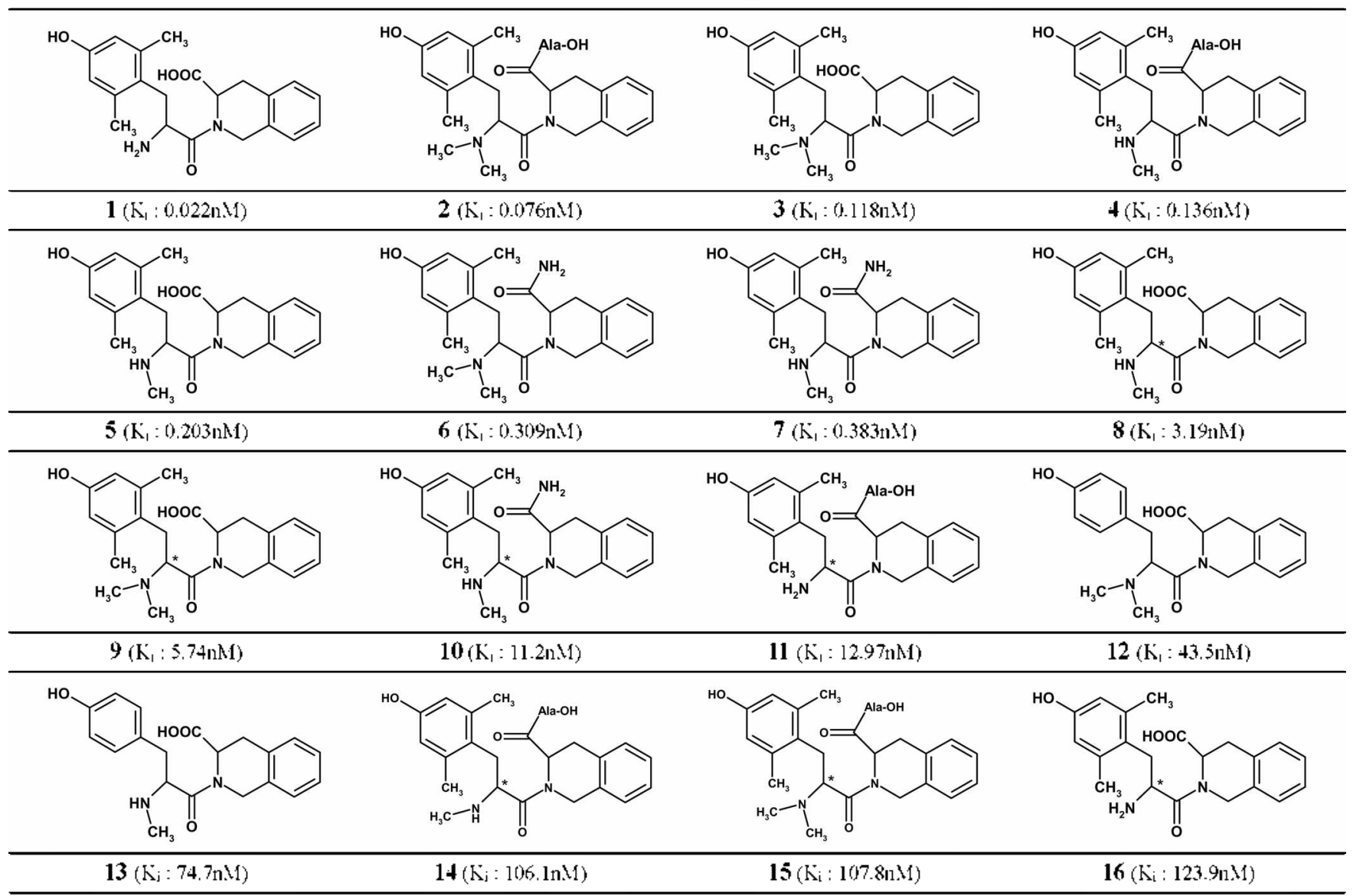

the probability of identifying the most important features for ligand recognition by comparing quantitative (Catalyst/ HypoGen) and qualitative (Catalyst/HipHop) methods. ${ }^{-4}$ These approaches have been successfully applied to DintTic derivatives ${ }^{250}$ and Naltrindole analogs. ${ }^{27.28}$

\section{Methods}

Catalyst/HypoGen. Training set is selected to generate hypotheses by considering structural diversity and wide coverage of the activity range. In this study, we constructed two training sets for HypoGen. The first set consisted of peptide antagonists (Peptide) of the $\delta$-opioid receptor that are derivatives of Dnt-Tic, and the second set is contained non-peptide antagonists (nPeptide) that are analogs of Naltrindole. These two sets included sixteen compounds that satisfy the selection rule for HypoGen generation. ${ }^{24}$ The secondary structures and activity values of the two sets are listed below in Tables 1 and 2 . Eleven chemical features were obtained from the Catalyst ${ }^{\mathrm{lM}}$ progran. We selected five feasible features-hydrogen bond acceptor (HBA). hydrophobic (HY), hỳdrophobic aliphatic (HAL), hỵdrophobic aromatic (HAR), and positive ionizable (PI) functions-based on analysis of the structurally and chemically important parts of the compounds. All ten hypotheses were proposed using HypoGen sorted according to the fitting and energy cut-off values with compounds within the training set.
Catalyst/HipHop. HipHop generates confomational models for each molecule in the training set. Each confonmer was examined for the presence of chemical features that are important in drug-enzyme (or receptor) interactions provided by Catalyst ${ }^{1 \mathrm{M}}$. The common features of HipHop are hydrogen bond donors (HBD) and acceptors (HBA). negative and positive charge centers. and hydrophobic regions. In the final step. a three-dimensional configuration of chemical features common to input molecules was determined. ${ }^{21}$ In this study. three launched opioid drugs (Naloxone ${ }^{2 y}$ Triazolam. ${ }^{3.1}$ and Cyclazocine ${ }^{3]}$ ) were selected as a training set to generate hypotheses. The structures and activities of the three drugs are presented in Table 3 .

We analyzed specific characteristics of the included features and compared the distance of each chemical feature for the best hypotheses obtained from the two different generation methods. HypoGen and HipHop.

Computational Methodology. Three-dimensional structures of compounds were generated and minimized using the Catalyst ${ }^{\mathrm{TM}}$ software package (Accelrys. San Diego, CA). Catalyst ${ }^{T \mathrm{M}}$ provides two different conformer generation methods. Best and Fast. Best generation method searches the confomational space more extensively than Fast generation and it applies more rigorous minimization procedures in both torsional and cartesian space ${ }^{\text {t- }}$ Fast generation searches confomations more roughly, therefore it spends considerably less computational time than Best. ${ }^{-4}$ 
Table 2. Training set molecules of non-peptide $\delta$-opioid antagonists of Naltrindole analogs for HypoGen generation (Activities are presented as $K_{\mathrm{i}}$ values)

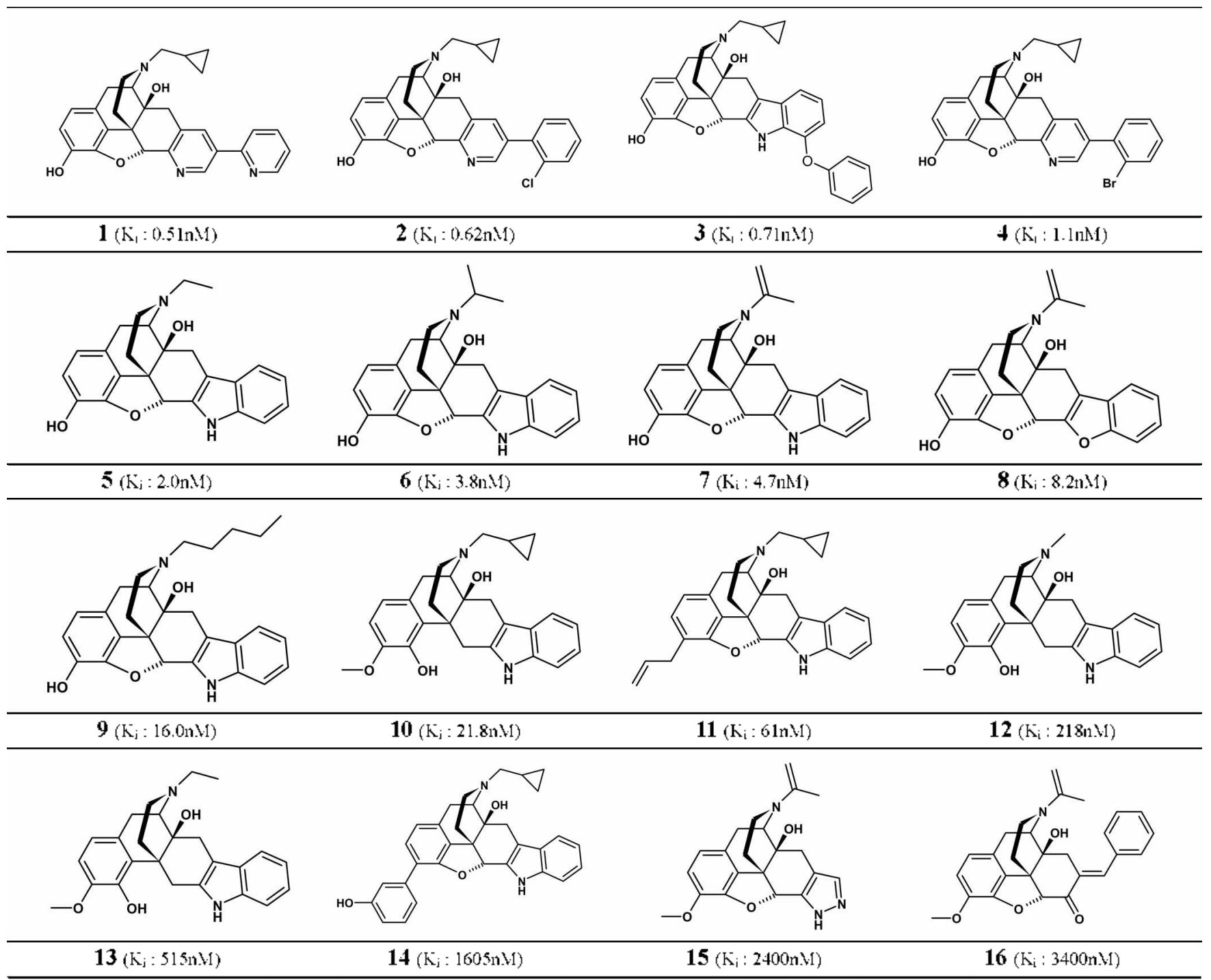

Table 3. Training set of three lannched opioid drugs for HipHop generation

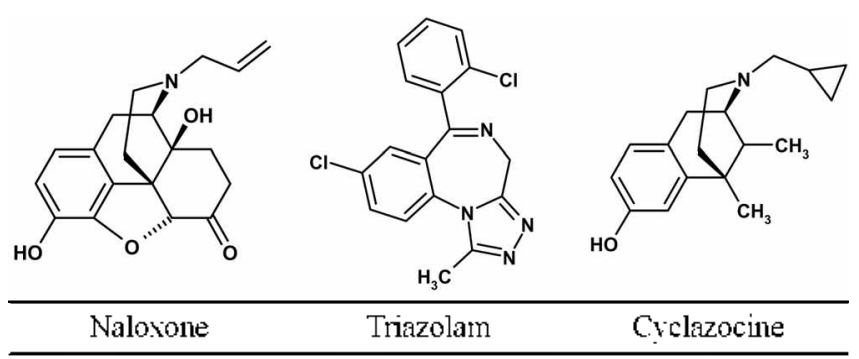

In this study. conformer generation was performed using Best generation method and the naximum number of conformers was determined as 250 within a $20 \mathrm{kcal} / \mathrm{mol}$ cutoff range. All conformations in the training sets were minimized to the find local minimum based on CHARMm force field and confomational analysis of each compound was implemented using the Poling algorithm for the search into unexplored regions of confonmer space. ${ }^{37.33}$ All other para- meters were used according to their default values. These computational studies were performed on a Silicon Graphics O2 R12000 workstation.

\section{Results and Discussion}

HypoGen: Ligand-Based Pharmacophore Model. The HỵpoGen pharmacophore model identifies chemical functional features that are typical of active compounds. thus facilitating their differentiation from inactive compounds. ${ }^{2+}$ Two training sets were selected by considering the structural diversity which represented covering a range of activities at least four orders of magnitude. Activity range of peptide antagonist is wide coverage in tenms of $\mathrm{K}_{\mathrm{J}}$ value from 0.002 $\mathrm{nM}$ to $120 \mathrm{nM}$ and non-peptide antagonist model is populated from $0.51 \mathrm{nM}$ to $3400 \mathrm{nM}$. Hỵpotheses were generated for each peptide and non-peptide antagonist of the $\delta$-opioid receptor, and the training set was submitted to a score hy pothesis. We estimated the activities of all training set compounds using this hypothesis. ${ }^{24}$ HypoGien produced 
Table 4. Actual and estimated activities of the peptide antagonist set based on Hypol

\begin{tabular}{cccccccc}
\hline Peptide & $\begin{array}{c}\text { Confor- } \\
\text { mation } \\
\text { Number }\end{array}$ & Act $^{a}$ & Est. $^{b}$ & Error & $\begin{array}{c}\text { Fit } \\
\text { Value }\end{array}$ & $\begin{array}{c}\text { Act. } \\
\text { Scale }^{c}\end{array}$ & $\begin{array}{c}\text { Est. } \\
\text { Scale }\end{array}$ \\
\hline 1 & 72 & 0.022 & 0.15 & +6.7 & 14.52 & +++ & +++ \\
2 & 193 & 0.076 & 0.099 & +1.3 & 14.69 & +++ & +++ \\
3 & 4 & 0.12 & 0.12 & -1.0 & 14.63 & +++ & +++ \\
4 & 74 & 0.14 & 0.039 & -3.5 & 15.10 & +++ & ++ \\
5 & 45 & 0.2 & 0.26 & +1.3 & 14.27 & +++ & ++ \\
6 & 4 & 0.31 & 0.25 & -1.2 & 14.29 & +++ & ++ \\
7 & 6 & 0.38 & 0.3 & -1.3 & 14.21 & +++ & ++ \\
8 & 52 & 3.2 & 1.7 & -1.9 & 13.46 & ++ & ++ \\
9 & 13 & 5.7 & 12 & +2.2 & 12.59 & ++ & ++ \\
10 & 29 & 11 & 21 & +1.9 & 12.36 & ++ & + \\
11 & 206 & 13 & 26 & +2.0 & 12.27 & ++ & + \\
12 & 65 & 43 & 76 & +1.7 & 11.81 & ++ & + \\
13 & 109 & 75 & 51 & -1.5 & 11.98 & ++ & + \\
14 & 42 & 110 & 71 & -1.5 & 11.84 & + & + \\
15 & 134 & 110 & 41 & -2.6 & 12.08 & + & + \\
16 & 44 & 120 & 47 & -2.6 & 12.01 & + & + \\
\hline
\end{tabular}

${ }^{2}$ Act. Actual (Experimental) activity (nM) ${ }^{b}$ Est. Estimated activity (nM) 'Act. scale: Activity scale +-- highly active $(e 1 \mathrm{nM})$-- moderatel active $(1-100 \mathrm{nM})$, + inactive ( $100 \mathrm{nM})$. "Est. Scale Estimated activity scale

Table 5. Actual and estimated activities of the non-peptide antagonist set based on nHypol

\begin{tabular}{rccccccc}
\hline nPeptide & $\begin{array}{c}\text { Confor- } \\
\text { mation } \\
\text { number }\end{array}$ & $\begin{array}{c}\text { Fit } \\
\text { Value }\end{array}$ & Act. $^{a}$ & Est. $^{b}$ & Enor & $\begin{array}{c}\text { Act. } \\
\text { Scale }^{r}\end{array}$ & $\begin{array}{c}\text { Est. } \\
\text { Scale }\end{array}$ \\
\hline 1 & 24 & 11.73 & 0.51 & 1.2 & +2.3 & ++ & ++ \\
2 & 16 & 11.39 & 0.62 & 2.6 & +4.1 & ++ & ++ \\
3 & 22 & 11.37 & 0.71 & 2.7 & +3.8 & ++ & ++ \\
4 & 12 & 11.15 & 1.1 & 4.4 & +4.0 & ++ & ++ \\
5 & 7 & 11.75 & 2 & 1.1 & -1.8 & ++ & ++ \\
6 & 8 & 11.39 & 3.8 & 2.6 & -1.5 & + & + \\
7 & 11 & 11.11 & 4.7 & 4.9 & -1.0 & ++ & + \\
8 & 2 & 11.54 & 8.2 & 1.8 & -4.5 & ++ & + \\
9 & 18 & 11.15 & 16 & 4.5 & -3.6 & ++ & + \\
10 & 10 & 10.59 & 22 & 16 & -1.3 & ++ & ++ \\
11 & 5 & 10.08 & 61 & 53 & -1.2 & ++ & ++ \\
12 & 3 & 8.55 & 220 & 1800 & +8.2 & + & + \\
13 & 4 & 8.98 & 520 & 660 & +1.3 & + & + \\
14 & 7 & 8.72 & 1600 & 1200 & -1.3 & + & + \\
15 & 6 & 8.87 & 2400 & 860 & -2.8 & + & + \\
16 & 5 & 9.08 & 3400 & 520 & -6.5 & + & + \\
\hline
\end{tabular}

"Act. Actual (Experimental) activity (nM). "Est. Estimated (predicted) activity (nM). 'Act. Scale (Activity scale): +-- highly active ( $1 \mathrm{nM}$ ). -- moderately active (1-100 nM), + inactive (o $100 \mathrm{nM}){ }^{d}$ Est. Scale Estimated activity scale

the top 10 scoring hypotheses. of which Hypol was the best hypothesis. Hypol exhibits the best correlation coefficient. highest cost difference. lowest error cost closest weight cost to 2. and a correlation of $96 \%$ and $98 \%$ between actual (or experimental) and estimated (or predicted) activities. as shown in Tables 4 and 5 . The fit value is high when each chemical feature in the hypothesis matches the active part of the ligand to a reasonable extent. All compounds in both training sets were classified into three activity scales. for example: highly active $(<\mathrm{lnM} .++)$. moderately active ( 1 $100 \mathrm{nM} .++)$. and inactive $(>100 \mathrm{nM} .+)$. Out of the 16 compounds in the peptide antagonist model. three moderately active peptides were predicted as inactive, and within the non-peptide antagonist training set, three highly active non-peptide compounds were predicted as moderately active. The degree of activity of compounds in both training sets was predicted accurately. In the peptide antagonist model, the total fixed cost of 10 hypotheses was 60.75 . and the null cost was 112.65 . Thus. the range between the fixed and null costs was 51.90 . When this range is over 60 bits. the hypotheses are very credible with $90 \%$ reliability. and at over 40 bits, reliability is about $75 \%^{2+34}$ The correlation coefficient of Hypol. 0.957. shows good correlation by linear regression of the geometric fit index. The RMSD value indicates the degree of reliability of the prediction for the training set. In this model. the RMSD of Hypol was 0.7142 , signifying good prediction.

The best hypothesis. Hypol. comprised five features. one HAR, two HAL, one HBD, and one PI function. Chemical features included in Hypol matched well the known essential characteristics of opioid receptor antagonists, such as the aromatic hydrophobic part of Tyr, hydrophobic region of Phe, and positive ionizable function of the nitrogen atom of the amine group. ${ }^{35,36}$ The most active peptide antagonist in the training set. Peptide 1 , exhibits a good fit with all five features of Hypol. Two HARs in Hypol are mapped to the phenyl ring of Dint and Tic regions in the peptide ligand. $\mathrm{HY}$ is mapped to a methyl group of Dint. HBD fits to the carboxylic acid of Tic, and PI fits to an amine group. The least active peptide antagonist. Peptide 16 , exhibits a low fit value with Hypol, and in particular. HBD or $\mathrm{HY}$ is not matched with any part of Peptide 16 and rest low active peptides in the training set. Mapping models between Hypol and Peptide 1. and Hypol-Peptide 16 are depicted in Figure 2. The positive charge of nitrogen on an amine group and aromatic ring region of the ligand. essential features for antagonism of the $\delta$-opioid receptor. are effectively represented in Hypol.

In the non-peptide model, the total fixed cost of 10 hypotheses is 67.47, and the null cost is 109.89 . Thus. the range between the fixed and null costs is 42.42 bits. As mentioned above. these data confirm that the top 10 hypotheses effectively describe the training set. The best hypothesis from the non-peptide model (designated nHypol) consisted of four chemical features. specifically. one HY, one HAR. one HAL and one PI. The correlation coefficient of nHypol is 0.92. and RMSD is 1.0203. Figure l(b) represents the correlation diagram. The $\mathrm{nHy}$ pol hypothesis satisfied conditions for the aromatic ring and positive charged regions. similar to Hypol. HAR or HY of nHypol is not mapped with any part of low activity non-peptide antagonists. this may explain the reason why the fit value of low activity antagonists is not good. Mapping models of 
(a)

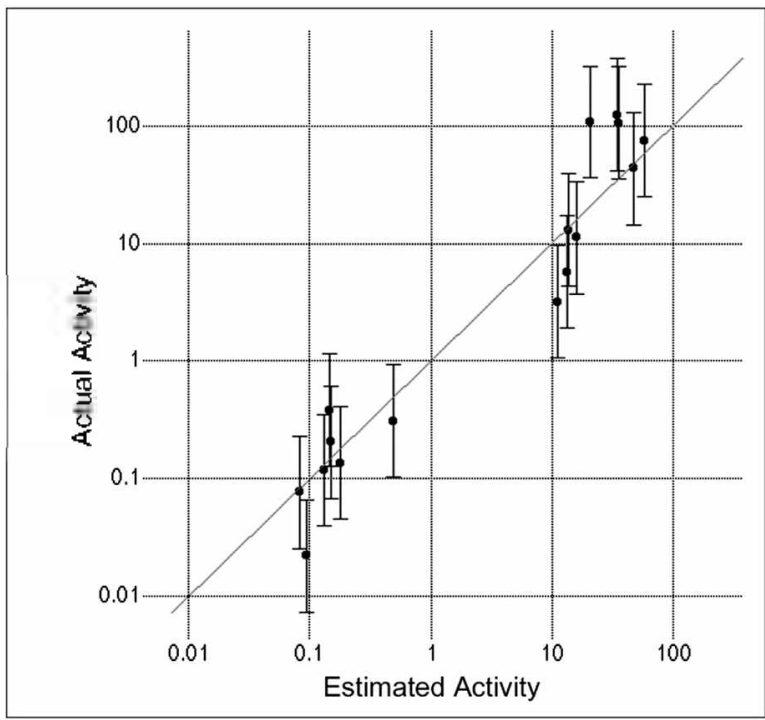

(b)

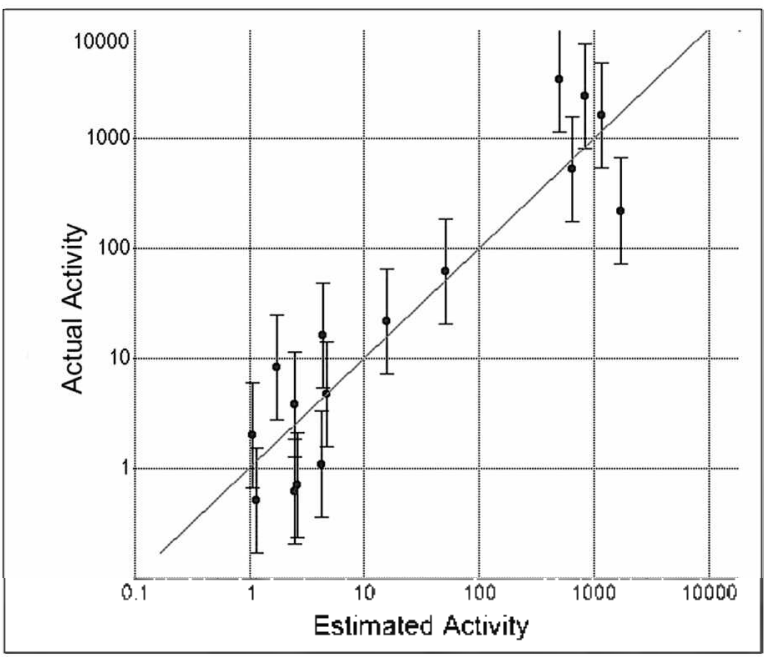

Figure 1. Regression diagram of actual versus estimated activities by Hypol for the training set. (a) Peptide antagonist model (b) Non-peptide antagonist model.

nHypol and non-peptide antagonists are presented in Figure 3.

Among the two hypotheses (Hypol and nHypol). only three features corresponded to those of an opioid antagonist. specifically, a hydrophobic region, an aromatic ring and a positively charged nitrogen region. The aromatic ring region of the peptide model was defined as 'hy'drophobic aromatic' (HAR), and similar feature was substituted for the hydrophobic (HY) function in the non-peptide model. PI is commonly defined as a nitrogen atom in both models. In Figure 4. we compare the distance and location of identical features between $\mathrm{Hyy}_{\mathrm{y}} \mathrm{pol}$ and $\mathrm{nH}_{\mathrm{y}} \mathrm{pol}$. Three identical features formed a triangular shape. The distances and locations of all features were similar between the two hypotheses. The average distance was $5.76 \AA$ for HY-PI. $5.19 \AA$ for HAR-PI. and $7.38 \dot{A}$ for HY-HAR. The distance between HY and HAR in the peptide model was shorter than that in the nonpeptide model. This may explain why the conformation of peptide antagonist is more flexible than that of the non- (a)

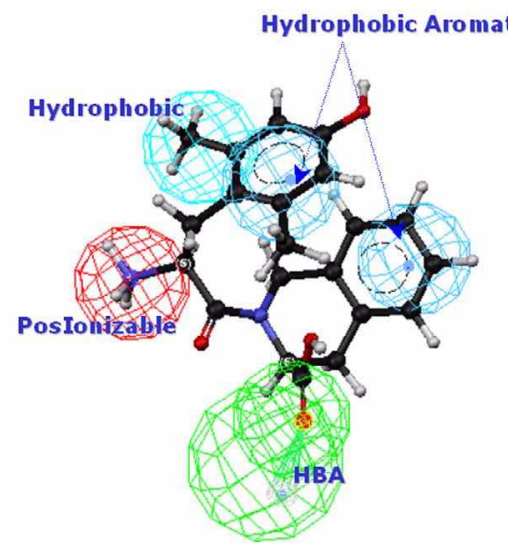

(b)

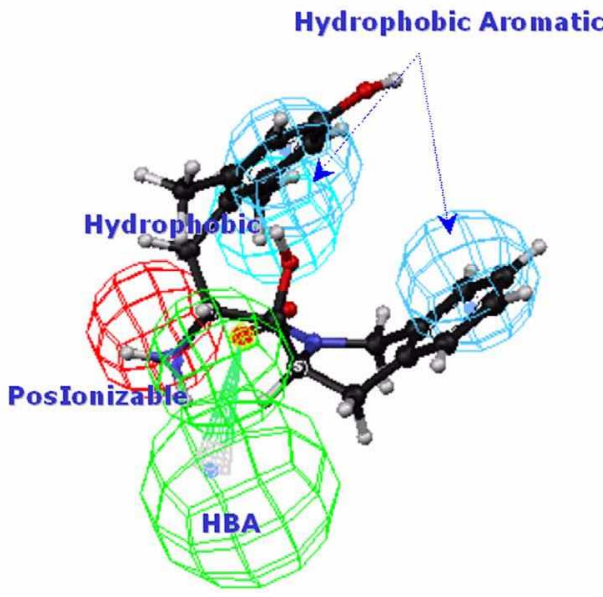

Figure 2. Mapping of the (a) highly active peptide ligand (Peptide 1) and (b) peptide ligand (Peptide 16) with lowest activity onto Hypol.

(a)

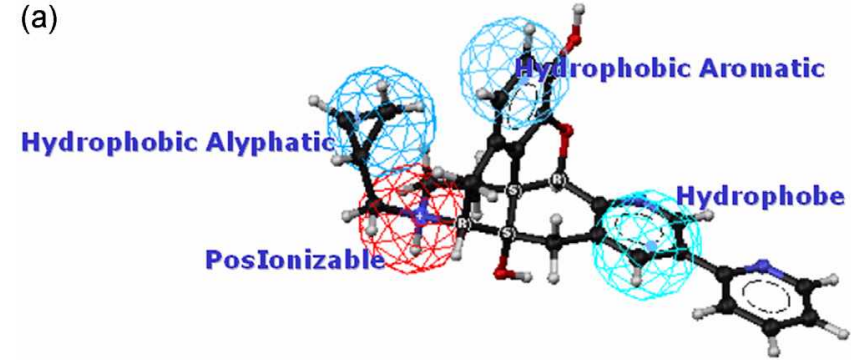

(b)

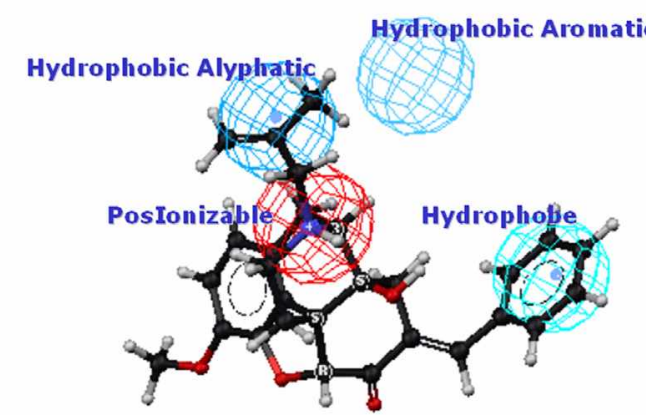

Figure 3. Mapping of the (a) highly active non-peptide ligand (nPeptide 1 ) and (b) non-peptide ligand (nPeptide 16 ) with lowest activity onto $\mathrm{nHypol}$. 


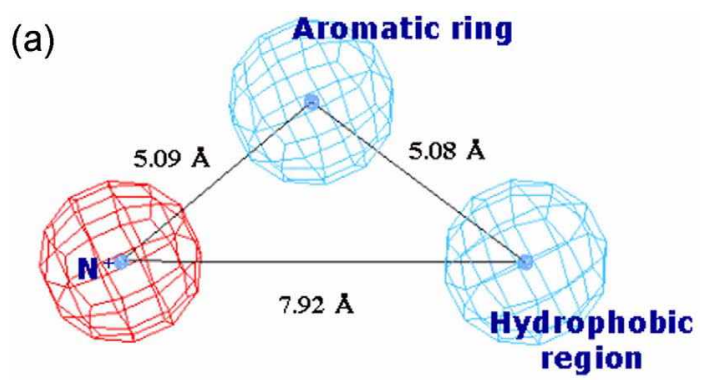

(b)

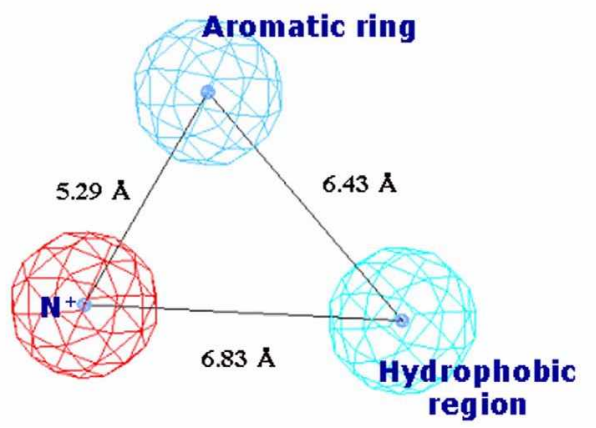

Figure 4. Comparison of the two hypotheses from HypoGent. (a) Hypol, the best hypothesis from the peptide antagonist model. (b) $n$ Hypol, the best hypothesis from the non-peptide antagonist model.

peptide antagonist.

HipHop: Common Feature-based Pharmacophore Model. To deternine the most advantageous phannacophore in the design of opioid dnigs. we additionally applied the Catalyst/HipHop method to generate a qualitative common feature model. and compared the hypothesis obtained with HypoGen. HipHop generates hypotheses based on only the identification and overlay of common features using known active ligands, and not activity data. Accordingly, we selected three launched opioid drugs for the training set. Naloxone. Triazolam, and Cyclazocine. There are nonopioid CNS drugs generally used to reduce the rates of fatal overdose associated with high concentrations of morphinelike drugs. To predict a more common pharmacophore, we selected these drugs by considering a maximized structural diversity. Structures of these three drugs are depicted in Table 3. The best hypothesis from HipHop (hHypo) consisted of a HAR. a HY. a HBD. and a PI. similar to that from HypoGen. The important features of hHypo were well characterized in the results of both HypoGen and HipHop. To identify common features among the three hypotheses (Hypol, nHypo 1, and hHypo), we superimposed the pharmacophores as shown in Figure 5. Remarkably on attempting to fit both training sets of HypoGen onto hHypo. we perceived that the most active peptide (Peptide 1) and non-peptide (nPeptide 1) antagonists mapped well onto hHypo in terms of all the specified features. The mapping models of Peptide 1 and nPeptide 1 onto hHypo are presented in Figure 6. Accordingly we propose that the three hypotheses determined using HypoGen and HipHop reveal essential pharmacophore features for the antagonism of $\delta$ -

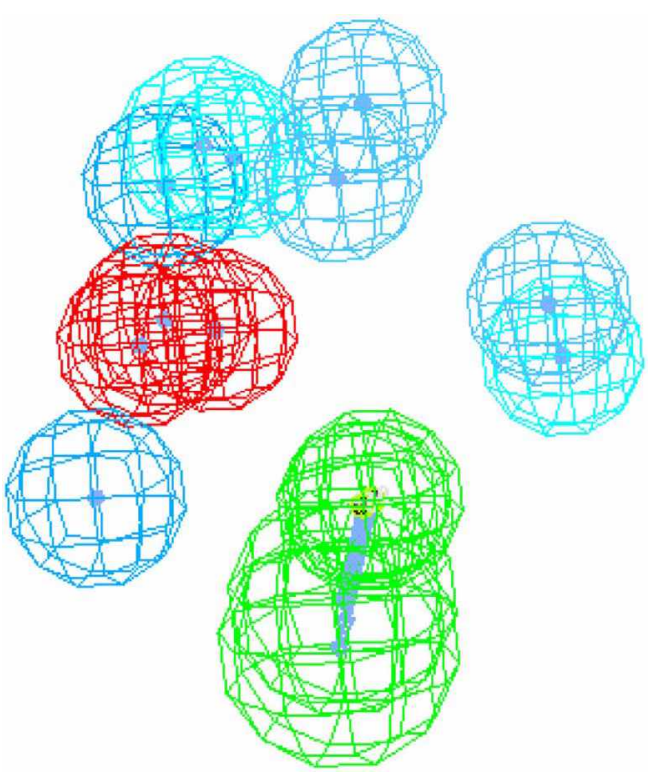

Figure 5. Superimposition of three hypotheses generated from HypoGen and HipHop. (a) Peptide l (b) nPeptide 1 .

(a)

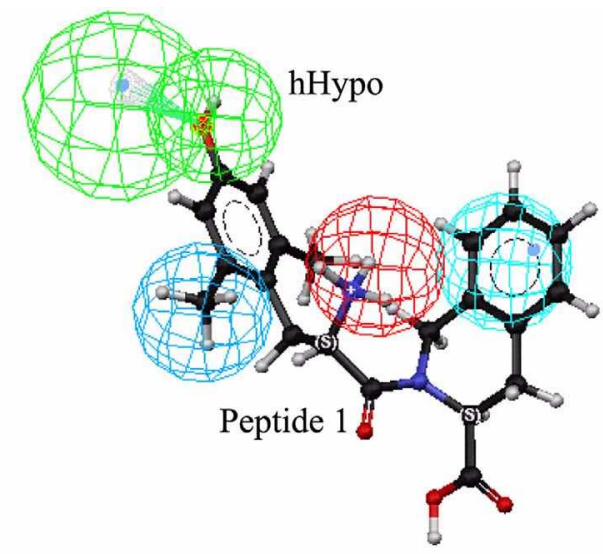

(b)

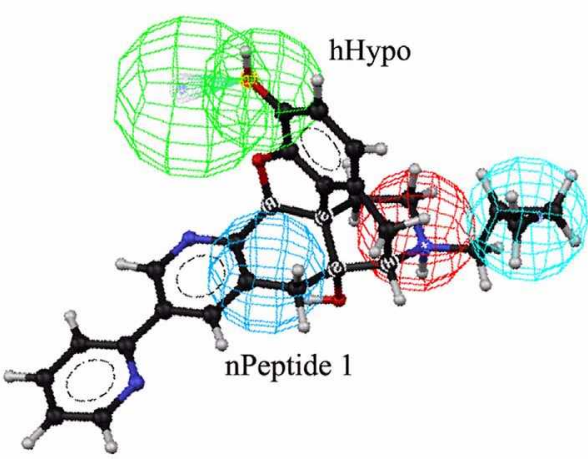

Figure 6. Mapping of (a) Peptidel and (b) nPeptide 1 onto the best hypothesis from HipHop (hHypo).

opioid receptor activity, which should aid in the effective design of highly potent $\delta$-opioid receptor antagonists.

\section{Conclusions}

In this study, we performed 3D-(QSAR for $\delta$-opioid receptor antagonists with the aid of quantitative and qualitative 
pharmacophore models applying two different ligand-based pharmacophore generation approaches. For the HypoGen experiments, we constructed two training sets for peptide and non-peptide antagonists, respectively. The best hypotheses, Hypol and nHypol. disclosed identical features. including an aromatic ring region and a positive charged nitrogen region. consistent with the essential characteristics of opioid antagonists. HipHop was performed using three launched opioid drugs as the training set. The best hypothesis. hHypo consisted of four common features (one hydrophobic aromatic. one hydrophobic, a hydrogen bond donor. and a positive ionizable function). The three hypotheses, Hypo 1, nHypo 1. and hHypo. exhibited three conmon features. specifically. a hydrophobic. a hydrophobic aromatic. and a positive nitrogen region. Our results support the utility of the essential phannacophore features obtained with these hypotheses, which effectively describe the structure-activity relationship for antagonists of the $\delta$-opioid receptor

Acknowledgments. This work was supported by the Research Program for New Drug Target Discovery (M10601000153-07N0100-15310) grant from the Ministry of Science \& Technology. South Korea. Ki-Woong Jeong is supported. in part by the second BK21 (MOE).

\section{References}

1. Marta. F.: Liisa. L.: Gilda. H. L. Protein Eng. 1999.12.927-942.

2. Przewlocki. R. Opioid Receptor Types and Subnpes: Relevance to Function and Drug Design in Towards a Kew Pharmacotherapy of Paim: Basbaum, A. I., Besson. I. M. Eds.: John Wiley: Chichester. 1991: pp 227-239.

3. Katzung. B. G. Basic \& Chical Pharmacologu 7ed: Appleton \& Lange: 1998.

4. Beddell C. R.: Clark R. B.: Lowe. L. A. Br. J. Pharmacol. 1977. $61,351-356$.

5. Casy A. F.: Partitt. R. T. Opioid Analgesics: Plenum Press: New York. NY. 1987

6. Hong. N. J.: Park. Y. T.: Lim. J. W.: Lee. C. W.: Koock. S. U. Korean J. led Chem. 1991. I. 4t

7. Millan, M. J. Trends Pharmacol. Sci. 1990, 11.70-76

8. Rapaka, R. S. Porteca, F. Pham Res. 1991. 8. 1-8.

9. Gilda. H. L. Moden Drug Discovern 1999, 2. 24-30.

10. Bilsky. E. J.: Calderon. S. N.: Wang. T.: Bernstein. R. N.: Davis. P.: Hruby. V. J.: McNutt. R. W.: Rothman. R. B.: Rice. K. C.: Porreca. F. J. Pharmacol Exp. Ther: 1995 273. 359-366.

11. Tseng. L. F: Narita. M.: Mizoguchi. H.: Kawai. K Mizusuna. A.: Kamei, J.: Suzuki. T.: Nagase, H. J. Pharmacol. Exp. Ther: 1997. 280, 600-605.

12. Dondio. G.: Ronzoni. S.: Petrillo. P. Exp. Opin. Ther Patents
1997. 7. 1075-1098

13. Arakawa. K:: Akami. T.: Okamoto. M.: Oka. T: Nagase. H.: Matsumoto. S. Tronsplantation 1992. 53.951-953.

14. Arakawa, K.: Akami, T; Okamoto, M.: Nakajima, H.; Mitsuo. M.; Naka I.: Oka, T.; Nagase, H. Transplant Proc. 1992. 24.696697.

15. Arakawa. K.: Akami. T.: Okamoto. M.: Akika. K.: Akai. I.: Oka. T.: Nagase. H. Transplant Proc. 1993. 25.738-740.

16. Fundytus. M. E.: Schiller. P. W: Shapiro. M: Weltrowska. G: Coderre, T. J. Regul. Pept. 1994. 54,97-98

17. Andrew, C.: Richard. B. R.: Christina. D.: John. P.; Frank, P.; Peg. D.; Arthur. E. J.: Kenner, C. R. J. Hed Chem 1999. 42. 1673 1679.

18. Lee. I. Y.: Lee. K. A.: Lee. B.: Chi. D. Y.: Kim. C. K. Bull. Korean Chent Soc. 2006. 27. 1969-1975.

19. Lee. D. Y.: Hyum. K. H; Park. H. Y.: Lee K. A.; Lee. B.; Kim. C. K. Bull Korean Chem. Soc. 2006, 27. 273-276.

20. Cheng C.: Peter. W. S. Eur d. of Pharmacet Sci. 2006, 27. 411424.

21. Clement. O. O.: Freemant. C. M.: Hartmant1. R. W.: Hadratta. V. D.: Vasaitis. T. S.: Brodie. A. M. H.: Njar. V. C. O. J. Med. Chent. 2003. $16,2345-2351$

22. Amor. A. S. J:- Cho. S. J. Bull. Korean Chem Soc. 2005. 26.952957.

23. Osmant. G.: Omoshile. C.: Yasuhisa. K. Cmm Med. Chem. 2004. 11. 2991-30015.

24. CATAIST. Version 4.7 Sottware: Copyright Accelrys Inc.: 2002.

25. Severo. S.: Giantranco. B.: Remo. G.; Roberto. T: Clementina. B. Sharon, D. B.: Peter. S. C.: Lawrence, H. L. J. Mfed. Chem 1997. 40. $3160-3108$

26. Sherita. M.: Thomas. U.: Richard. B. R.: Heng. X.: Christina. D.: Andrew C.: Peg. D.: Fratk. P.: Atthur. E. J.: Kenter. C. R. J. Med. Chent 2001. H4. 1471-1474.

27. Han. Y.: Thomas. P: Christina, M. D.: Jamila, M.: Richard. B. R: Arthur. E. J.; Kenner. C. R. Bioorg. 1fed. Chem. Lett. 2002, 12. $165-168$.

28. Andrew: C.: Julia. P.: Lijuan. W: Karen. M.: Richard. B. R.: Christine. D.: Arthur. E. T.: Kent1er. C. R. Bicorg. Hed. Chent. Letf. 1999. 9. 3435-3438.

29. Thomas, U.: Christina, M. D.; Richard, B. R.; Arthur, E. J.; Kenner. C. R. Bioong Hed Chem Lett 2001, 11.2883-2885.

30. Hitoshi, K: Richard. B. R.: Chris, D; Karen. M.: Julia, P: Kenner. C. R. Bioong. Med Chent Lett. 1998. 8. 799-804.

31. Giulio. D.: Silvano. R.: Paola. P. Exp. Opin. Ther Patents 1999.9. 353-374

32. Liu. F.: You, Q.: Chen. Y. Bioong. 1fed. Chem. Lett. 2007. 17,722 726 .

33. Li. M.: Tsai, K.: Xia. L. Bioorg. Med. Chem. Lett. 2005. 15.657664.

34. Eva. M. K.: Thierry. L. J. Med Chent 2003. 46.716-726.

35. Sharon. D. B.: Clifford. G.: Judith. L. F.: Jeffrey. R. D.: Severo. S.: Gianfranco, B.: Remo, G.; Lawrence, H. L. J. Hed. Chem. 2002. 45. 5506-5513.

36. Gianfranco, B.; Severo, S.; Remo, G; Lucia, N.; Elisa, G.: Sharon. D. B.: Yunden. T.: Lawrence. H. L. J. Hed. Chen 2004. 47. 40664071 . 